\title{
Die Redaktion stellt sich vor
}

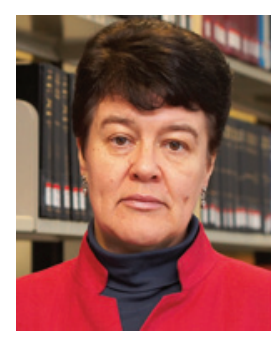

\section{Dr. Annette Gerlach}

Nach Studium und Promotion erfolgte die bibliothekarische Ausbildung an der UB Freiburg und der Bibliotheksschule Frankfurt/Main. Sechs Jahre Leitung der Wissenschaftlichen Bibliothek der Anhaltischen Landesbücherei Dessau (sowie der stellv. Direktion der Gesamtbibliothek). Danach folgten 13 Jahre Tätigkeit in der Zentral- und Landesbibliothek Berlin mit den Zuständigkeiten für die Historischen Sammlungen, Bestandserhaltung u. a. Dort war ein Themenschwerpunkt der Aufbau des „Kompetenzzentrums Bestandserhaltung für Bibliotheken und Archive in Berlin und Brandenburg“. Die Thematik der Raubgutprojekte (also der Recherche nach ns-verfolgungsbedingt entzogenem Kulturgut) wurde im Laufe der Jahre zudem immer wichtiger. Seit Ende 2011 Mitarbeit in der Redaktion der Zeitschrift „Bibliothekdienst“.

Die Übernahme der Leitung des Landesbibliothekszentrums Rheinland-Pfalz erfolgte im Dezember 2012.

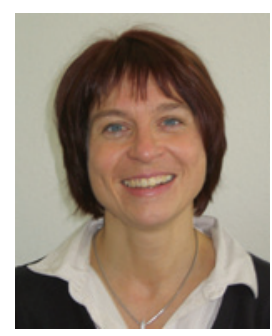

\section{Dr. Barbara Koelges}

Ausbildung zur Diplombibliothekarin an wissenschaftlichen Bibliotheken an der UB Mainz 1983-1986. Studium Sozialwissenschaften, Neuere Geschichte, Neuere Deutsche Literaturwissenschaft Fernuniversität Hagen; Magisterabschluss 1996, Promotion 2001. Referendariat Rheinische Landesbibliothek Koblenz und Bibliotheksschule Frankfurt 2002-2003. 
Seit 2004 Referentin für Presse- und Öffentlichkeitsarbeit des Landesbibliothekszentrums Rheinland-Pfalz. Fachreferentin für Wirtschaft, Soziologie, Philosophie, Theologie, Germanistik, Handschriften und alte Drucke in der Rheinischen Landesbibliothek Koblenz.

Seit März 2013 Mitarbeit in der Redaktion der Zeitschrift „Bibliotheksdienst“.

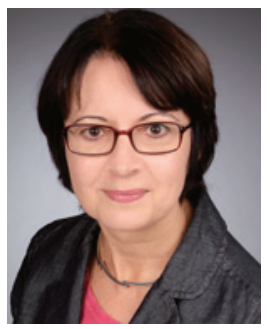

\section{Dr. Petra Weiß}

1980-1992 Ausbildung zur Bankkauffrau und anschließende Berufstätigkeit, 1989-1998 Teilzeitstudium Sozialwissenschaften, Geschichte und Neuere Deutsche Literaturwissenschaft an der Fernuniversität in Hagen, 1998 MagisterAbschluss, 1998-2005 freiberufliche Tätigkeit (u.a. Ausstellungs- und Buchprojekte), seit 2005 Teilzeitangestellte im Stadtarchiv Koblenz, 2012 Promotion im Fach Geschichte, seit Mai 2013 nebenberufliche Redaktionsassistenz für die Zeitschrift „Bibliotheksdienst“. 